of diminishing this serious evil. A further subcommittee was appointed to collate information with regard to Nature reserves throughout Europe with the view of promoting the establishment of further areas for this purpose. M. Jean Delacour (France) was elected president of the International Committee, Mr. Hoyes Lloyd (Canada) and Dr. P. G. van Tienhoven (Holland) vice-presidents, Mr. Percy $\mathbf{R}$. Lowe (Great Britain) Chairman of the national sections of Europe, and M. Leon Lippens (Belgium) and Miss Phyllis Barclay-Smith (Great Britain) were reappointed secretaries. A message expressing his interest and wishing success to the meeting was received from the Prime Minister of Great Britain.

\section{Pre-Folsom Man in America}

SHould preliminary accounts of the discovery of stone implements in Lake County, California, be confirmed in detail, it may be regarded as established that man existed in America in a period prior to that of the Folsom implements of the south-western United States, hitherto generally accepted as the earliest handiwork of man yet found on the American continent. According to a statement circulated by Science Service, of Washington, D.C., a joint expedition of the Carnegie Institution of Washington and the South-West Museum, Los Angeles, under the direction of Mr. M. R. Harrington, has found in ground disturbed by the plough on the shore of a brackish pond, Folsom implements in association with others of the Mohave type-a type recently found at Lake Mohave and another site, but of which the relation to the Folsom industry was in doubt. Further excavation on the Lake County site revealed the existence of a camp deposit, in which the Mohave type of implement occurred definitely below and antedating the Folsom implements. At about the same level was a new type of spear-head, to which the name of Borax Lake type has been given. Even more remarkable, however, was the discovery at a still lower level of older and cruder implements, mainly large scrapers and hand axes, belonging to a people "as yet an entirely unknown quantity in American archæology". It is calculated that on a conservative estimate this discovery would allow man on the American continent an antiquity of at least fifteen thousand years, as against the seven to twelve thousand years variously accepted for Folsom man.

\section{Early Hebrew Script at Lachish}

ON the return to England of the members of the Marston-Wellcome Archæological Expedition to Lachish at the close of excavations for the season 1937-38, further discoveries of examples of early Hebrew seript on this site are reported (The Times, May 26). Three fragments of pottery have been found, which are inscribed in the Phenician-Hebrew script used in the famous Lachish letters, as well as scribings on the steps of the Lachish palace. The first of the three sherds shows five names of persons, followed by numerals, which probably represent quantities of wheat, oil or other commodity. The second sherd was found in a room with the remains of the pot from which it was broken, and is thought to be a receipt. The inscription begins with the phrase "In the ninth year", serving to recall the fact that it was in the ninth year of the reign of Zedekiah that Nebuchadnezzar came to Jerusalem and besieged it. As the house in which this sherd was found shows signs of having been burnt, it is thought possible that the receipt may have been written immediately before Nebuchadnezzar's second attack on Lachish in 588 B.c. The third inscription presents a certain similarity to the Lachish letters. It is very small, but there is writing on both sides, and it is evidently a letter, beginning "To my Lord". These inscriptions have been submitted to Prof. H. Torczyner, who was responsible for the decipherment of the series of eighteen letters discovered in $\mathbf{1 9 3 5}$. The scribings on the face of one of the steps of the Palace, which the expedition is now beginning to excavate, are thought to have been the work of a schoolboy. With a rectangular drawing with lines across, and the picture of a lion, are the first five letters of the PhenicianHebrew alphabet. These, reading from left to right, are in the same order as our alphabet, and are the earliest evidence for that order. They date from before Nebuchadnezzar's earlier destruction of Lachish in 597 B.c. From these discoveries the inference is drawn that the Phenician-Hebrew script was in general use in the kingdom of Judah and was being taught in the schools before the Captivity. After the Captivity the Assyrian-Hebrew script was employed.

\section{Infestation of Grain by Insects}

DESTRUCTION of stored grain and grain products by insects causes great loss to many sections of industry, probably amounting annually to not less than $£ 500,000$. More information is required before the problem can be completely tackled. The first step is a scientific survey which is to be made at once, during the period of seasonal activity of the insects. This survey has been organized on the initiative of the various sections of industry concerned, and the major part of its cost will be met by their contributions. It is to be carried out, under the auspices of the Department of Scientific and Industrial Research, by the Stored Products Laboratory of the Imperial College of Science and Technology. A conference has been formed of the representatives of interested bodies which have already agreed to co-operate in this work and its first meeting was held on May 26 in the offices of the Department of Scientific and Industrial Research. The cooperation of all sections of industry affected is essential to the success of any organized attack on these insect pests. The neglect of one section to play its part will jeopardize the success of the efforts of all the rest. The Conference, therefore, viewed with satisfaction the extent of the support so far accorded. Any organization or undertaking wishing to co-operate in this work should communicate with the Secretary of the Department of Scientific and Industrial Research, 16 Old Queen Street, Westminster, London, S.W.1. 